\title{
Constraints on long-term changes in solar activity from the range of variability of cosmogenic radionuclide records
}

\author{
R. Muscheler ${ }^{1}$ and U. Heikkilä ${ }^{2,3}$ \\ ${ }^{1}$ Department of Earth and Ecosystem Sciences, Division of Geology, Lund University, Sölvegatan 12, SE-22362 Lund, \\ Sweden \\ ${ }^{2}$ Uni Bjerknes Centre, Bjerknes Centre for Climate Research, Allegaten 70, NO-5007 Bergen, Norway \\ ${ }^{3}$ Australian Nuclear Science and Technology Organisation (ANSTO)
}

Received: 5 November 2010 - Revised: 25 January 2011 - Accepted: 21 March 2011 - Published: 8 September 2011

\begin{abstract}
There is a variety of different cosmogenic radionuclide-based reconstructions of solar activity variations for the past. Especially the longer-term changes and the absolute levels of past solar activity are uncertain as it is illustrated by the differences between these reconstructions. On the one hand there are differences between ${ }^{10} \mathrm{Be}$ and ${ }^{14} \mathrm{C}$ records that are commonly used as proxies for the varying solar modulation of galactic cosmic rays. On the other hand estimates of past changes in the geomagnetic shielding also include relatively large uncertainties. Here, we concentrate on variations in cosmogenic radionuclide records on time scales of 50 to $500 \mathrm{yr}$. We show that these are to a large extent independent of the geomagnetic field intensity. The range of variability of cosmogenic radionuclide records allows us to set constraints about long-term changes in solar activity. These records indicate that present solar activity levels were reached or exceeded regularly in the past.
\end{abstract}

\section{Introduction}

Cosmogenic radionuclides are the most reliable indirect recorders of past changes in solar activity. These particles are produced in the cascade of reactions in the atmosphere initiated by high-energy galactic cosmic rays (GCRs) (e.g. Lal and Peters, 1967). The solar and geomagnetic shielding of cosmic rays and consequently the production rates of cosmogenic radionuclides can be exploited for solar activity and geomagnetic field reconstructions. However, variations in the transport and deposition of cosmogenic radionuclides from their origin into the natural archives can complicate such calculations. For example, ${ }^{10} \mathrm{Be}$ has an average atmospheric residence time in the order of a year during which it is gen-

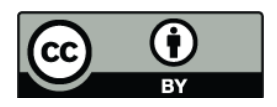

Correspondence to: R. Muscheler (raimund.muscheler@geol.lu.se) erally well mixed in the atmosphere. However, if the atmospheric circulation or deposition pattern were to change significantly during a longer period, ${ }^{10} \mathrm{Be}$ records would partly reflect the transport or deposition change in the atmosphere and not only the production signal. In the following we will also consider radiocarbon $\left({ }^{14} \mathrm{C}\right)$. After the production ${ }^{14} \mathrm{C}$ oxidises to ${ }^{14} \mathrm{CO}_{2}$ and gets incorporated into the carbon cycle. Therefore, ${ }^{14} \mathrm{C}$ records also reflect carbon cycle-related processes.

There are several reconstructions of past changes in solar activity for the Holocene period (e.g. Knudsen et al., 2009; Solanki et al., 2004; Vonmoos et al., 2006; Steinhilber et al., 2008). All of them are based on cosmogenic radionuclides but, while different radionuclide records agree generally well with respect to their short-term changes, there are differences in the long-term changes of ${ }^{10} \mathrm{Be}$ and ${ }^{14} \mathrm{C}$ records on time scales of millennia (Muscheler et al., 2004; Vonmoos et al., 2006). The origins of the differences are not yet resolved but they lead to a significant divergence in the reconstructed solar activity levels based on ${ }^{10} \mathrm{Be}$ and ${ }^{14} \mathrm{C}$ (Vonmoos et al., 2006).

In addition to differences between ${ }^{10} \mathrm{Be}$ and ${ }^{14} \mathrm{C}$ records there is also considerable uncertainty in the reconstructed geomagnetic field intensities (e.g. Knudsen et al., 2008). Nevertheless, reliable reconstructions of past changes in geomagnetic field intensity have been a prerequisite for an accurate separation between geomagnetic and solar influences on the ${ }^{10} \mathrm{Be}$ and ${ }^{14} \mathrm{C}$ production rates.

In the following we will present a method to constrain past changes in solar variability that is largely independent of the geomagnetic field uncertainties and that is not influenced by the long-term differences between the radionuclide records. Therefore, in contrast to earlier calculations our conclusions are not affected by these two major uncertainties for solar activity reconstructions. We will begin with a short review of the latest results on the local interstellar galactic cosmic ray spectra since these determine the possible range of variability

Published by Copernicus Publications on behalf of the Arbeitsgemeinschaft Extraterrestrische Forschung e.V. 


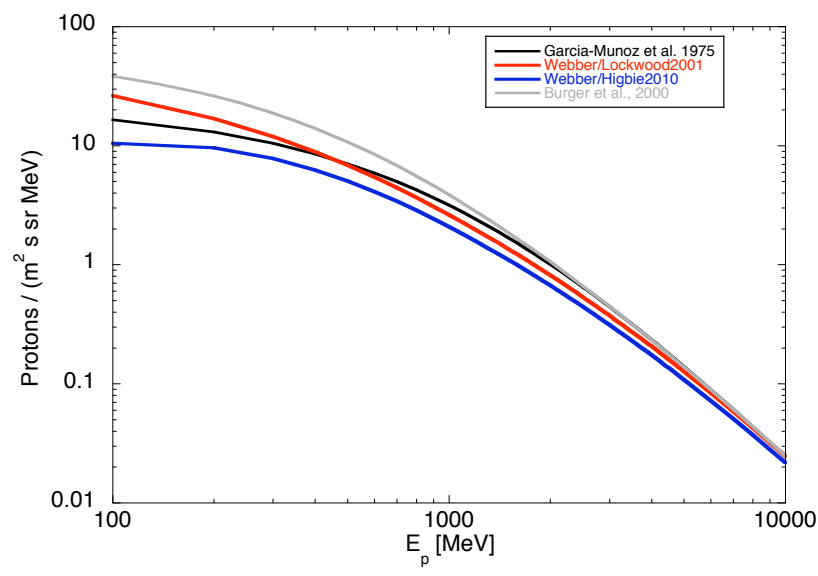

Fig. 1. Published GCR spectra for protons. There are significant differences in the lower energy range of the spectra and the most recent estimates (Webber and Higbie, 2010) suggest a smaller number of lower-energy protons in the spectra.

that can be expected from solar activity variations. This will be followed by a discussion of the geochemical behaviour of ${ }^{14} \mathrm{C}$ and ${ }^{10} \mathrm{Be}$ and potential biases in the reconstructed variations in ${ }^{14} \mathrm{C}$ and ${ }^{10} \mathrm{Be}$ production rates. We will discuss the robustness of our results via comparison of the ${ }^{10} \mathrm{Be}$ and ${ }^{14} \mathrm{C}$ based solar activity estimates.

\section{Theoretical background}

\subsection{Cosmogenic radionuclide production}

Cosmogenic radionuclides are produced by high-energy cosmic rays that manage to enter the Earths atmosphere through a shielding due to the heliospheric- and geo-magnetic field. ${ }^{10} \mathrm{Be}$ is produced in spallation reactions while ${ }^{14} \mathrm{C}$ is mainly produced by thermal neutrons captured by nitrogen (Lal and Peters, 1967). The production processes are well understood and can be modelled quantitatively (e.g. Masarik and Beer, 1999, 2009). These calculations require the knowledge of the primary GCR spectrum reaching Earth. For the interpretation of cosmogenic radionuclides the force-field approximation is a practical simplification (Gleeson and Axford, 1968). It describes the solar-modulated GCR spectra with a single parameter, the so-called solar modulation function $\Phi$. With higher solar activity (and larger $\Phi$ ) the lower energy particles get preferentially deflected and, in the vicinity of Earth, the GCR spectrum is depleted in low energy particles. Important for our considerations is also the GCR spectrum outside the heliosphere the so-called local interstellar spectrum (LIS). It determines the increase in GCRs from e.g. todays values compared to a period of low or absent solar magnetic shielding.

Figure 1 shows a variety of published GCR proton spectra outside the heliosphere i.e. with absent solar shielding. The different publications disagree significantly especially in the lower energy part of the LIS. This is mainly due to the fact that the relatively strong solar modulation since the beginning of such measurements obscured the lower energy range of the LIS. However, as the Voyager satellites approach the modulation boundary, the heliopause, it is possible to gain new insights into the GCR spectra. Using these data Webber and Higbie (2009, 2010) suggested updated GCR spectra (blue line in Fig. 1). Compared to earlier estimates (as e.g. Burger et al., 2000; Garcia-Munoz et al., 1975) there are fewer lower energy protons. This has profound effects on the interpretation of cosmogenic radionuclide records. Fewer particles in the local interstellar spectrum mean that the difference to the present GCR spectrum at Earth is smaller. Consequently, the newer LIS estimates imply a reduced increase in cosmic rays (and consequently in cosmogenic radionuclide production rates) that can be expected with lower or absent solar shielding (Webber and Higbie, 2010). In the following we will use the results of Masarik and Beer (1999, 2009) for our quantitative considerations. They based their calculations on the LIS published by Garcia-Munoz et al. (1975).

As a first approximation the results by Masarik and Beer $(1999,2009)$ can be transferred to other LIS models by adjusting the modulation function to the respective LIS spectra. Usoskin et al. (2005) suggested such conversion relationships optimized for GCR spectrum at $1 \mathrm{AU}$. Concentrating on the energy range relevant for the ${ }^{10} \mathrm{Be}$ production Steinhilber et al. (2008) found similar relationships. For example, a cosmic ray spectrum at Earth that corresponds to a modern solar 11-yr cycle minimum can be described with a solar modulation function of $400 \mathrm{MeV}$ in connection to the Burger et al. (2000) spectrum. Since the LIS by Garcia-Munoz et al. (1975) has fewer protons at lower energies a correspondingly smaller solar modulation function would represent a similar spectrum with this LIS. The energy dependence is different for the different spectra and, therefore, the suggested linear conversions of the solar modulation functions are just a first order approximation. Instead of simply comparing the spectra with the different LIS and different solar modulation functions it is more accurate to weigh the spectra with the yield functions for the radionuclide production rates (e.g. Webber and Higbie, 2003). For example, with the new LIS suggested by Webber and Higbie (2010) we get the same ${ }^{10} \mathrm{Be}$ production rate as with the LIS from Garcia-Munoz et al. (1975) modulated with a solar modulation function of about $160 \mathrm{MeV}$.

In conclusion, there are uncertainties in the different LIS suggestions and we have chosen to use the results based on the LIS published by Garcia-Munoz et al. (1975). Recent LIS suggestions are more deficient in low energy cosmic rays which leads to a more restricted range for cosmogenic radionuclide production rate variations. New results on the LIS could lead to minor modifications for our analysis but there are methods how, for example, the results of Masarik and 
Beer $(1999,2009)$ can be transferred to other LIS models.

\section{$2.2{ }^{10} \mathrm{Be}$ and ${ }^{14} \mathrm{C}$ production rate variability}

Masarik and Beer $(1999,2009)$ calculated the ${ }^{10} \mathrm{Be}$ and ${ }^{14} \mathrm{C}$ production rates in the atmosphere for a suite of solar and geomagnetic shielding scenarios. From their results we can obtain estimates of how much the globally averaged production rates can change depending on solar and geomagnetic shielding. Especially important for the following discussion is the increase in ${ }^{10} \mathrm{Be}$ and ${ }^{14} \mathrm{C}$ production rates that we can expect if the solar modulation would be absent, i.e. if GCRs can enter the solar system without being partly deflected by the Sun.

The relative increase of the ${ }^{10} \mathrm{Be}$ and ${ }^{14} \mathrm{C}$ production rates with lower solar shielding remained virtually unchanged with the new updated calculations of Masarik and Beer (2009). The results suggest that the globally averaged ${ }^{10} \mathrm{Be}$ production rate increases by $52 \%$ for absent solar shielding relative to an average ${ }^{10} \mathrm{Be}$ production rate during the last $60 \mathrm{yr}(\Phi \approx 700 \mathrm{MeV})$. The ${ }^{14} \mathrm{C}$ production rate reacts more sensitively to variations in solar shielding. The globally averaged ${ }^{14} \mathrm{C}$ production rate is estimated to increase by about $70 \%$ from a recent average solar activity to absent solar shielding (Masarik and Beer, 1999, 2009). Considering the recent revisions to the LIS these two numbers are rather upper estimates since, as mentioned before, the potential GCR increase compared to today is likely to be smaller as suggested by the LIS used by Masarik and Beer $(1999,2009)$.

Even though the ${ }^{10} \mathrm{Be}$ and ${ }^{14} \mathrm{C}$ production rates depend on the interplay between geo- and solar magnetic shielding the relative increases in ${ }^{10} \mathrm{Be}$ and ${ }^{14} \mathrm{C}$ production rates are surprisingly independent of the geomagnetic field intensity. Figure 2 shows the globally averaged ${ }^{14} \mathrm{C}$ production rates as a function of the solar modulation (Masarik and Beer, 1999). The different lines show this relationship for different geomagnetic field intensities. In fact almost all the curves lie on top of each other and indicate the same relative increase in the globally averaged ${ }^{14} \mathrm{C}$ production rate of about $70 \%$ for a change of the solar modulation function from $700 \mathrm{MeV}$ to $0 \mathrm{MeV}$. Only for very low geomagnetic field intensities ( $B=0$ and $B=1 / 4$ of todays values) these results suggest a larger increase.

\subsection{Geochemical behaviour of ${ }^{10} \mathrm{Be}$ and ${ }^{14} \mathrm{C}$}

After the production ${ }^{10} \mathrm{Be}$ and ${ }^{14} \mathrm{C}$ have a very different geochemical behaviour. ${ }^{14} \mathrm{C}$ oxidises to $\mathrm{CO}_{2}$ and enters the carbon cycle (e.g. Siegenthaler et al., 1980). By contrast, ${ }^{10} \mathrm{Be}$ gets attached to aerosols and becomes deposited onto the Earths surface within 1-2 yr (e.g. McHargue and Damon, 1991). Therefore, changes in these processes, such as a climate change, also affect the radionuclide concentrations in a different way. Hence, the different geochemical behaviour can be used to extract and isolate the common production

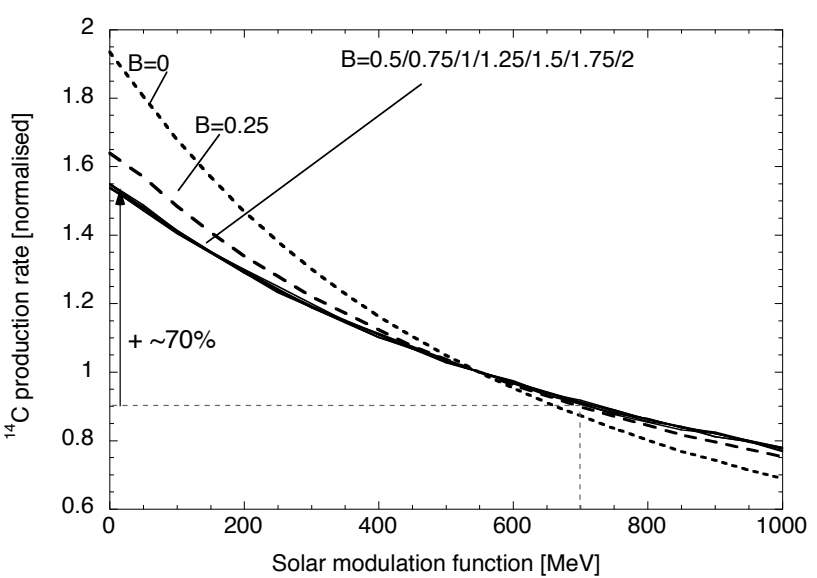

Fig. 2. Dependence of the globally averaged ${ }^{14} \mathrm{C}$ production rates on the solar modulation function. For most geomagnetic field intensities $(\mathrm{B}=0.5,0.75,1,1.25,1.5,1.75,2$ relative to todays value) the relative increase of the ${ }^{14} \mathrm{C}$ production rate with decreasing solar modulation is similar. One obtains an approximately $70 \%$ increase in the ${ }^{14} \mathrm{C}$ production rate with absent solar shielding compared to a solar modulation of $700 \mathrm{MeV}$. Only for very low geomagnetic field intensities ( $\mathrm{B}=0$ and 0.25 of todays value) this increase is larger. $\mathrm{A}$ similar figure applies for ${ }^{10} \mathrm{Be}$.

rate signal in ${ }^{10} \mathrm{Be}$ and ${ }^{14} \mathrm{C}$ records, and it allows us to study climate-related influences on ${ }^{10} \mathrm{Be}$ and ${ }^{14} \mathrm{C}$.

Since ${ }^{14} \mathrm{C}$ enters the carbon cycle its concentration in the atmosphere depends not only on the ${ }^{14} \mathrm{C}$ production rate but also on the exchange processes between atmosphere, biosphere, mixed layer and deep ocean. Freshly produced ${ }^{14} \mathrm{C}$, therefore, adds to a large reservoir of previously produced ${ }^{14} \mathrm{C}$. Hence, solar-induced ${ }^{14} \mathrm{C}$ variations appear only dampened and delayed in the atmospheric ${ }^{14} \mathrm{C}$ concentration. A carbon cycle model is required to take these processes into account in order to reconstruct the production signal. Delaygue and Bard (2010) show the attenuation and phase lag of atmospheric ${ }^{14} \mathrm{C}$ concentrations with respect to the ${ }^{14} \mathrm{C}$ production rate for a variety of different carbon cycle models. For typical solar changes on time scales of e.g. $200 \mathrm{yr}$ they obtain an attenuation factor of about 0.05 to 0.06 and a phase lag of about a tenth of the cycle length. This means that a solar cycle with a duration of $200 \mathrm{yr}$ and a ${ }^{14} \mathrm{C}$ production rate variation of e.g. $20 \%$ will produce an atmospheric ${ }^{14} \mathrm{C}$ variation of about $1 \%$ with maxima and minima that are delayed by about $20 \mathrm{yr}$. In the following we will show results from a box-diffusion carbon cycle model (Oeschger et al., 1975; Siegenthaler, 1983). The model-based attenuation factors and phase lags are in the same range as mentioned by Delaygue and Bard (2010) and results from the box-diffusion model agree well with results from more advanced 3-D carbon cycle models (Muscheler et al., 2007).

${ }^{14} \mathrm{C}$ has the advantage that the atmospheric residence time is long enough to allow ${ }^{14} \mathrm{C}$ to become well mixed in the 
atmosphere. This means that latitudinal differences in the ${ }^{14} \mathrm{C}$ production rates should not be visible and that the atmospheric ${ }^{14} \mathrm{C}$ concentrations measured at any latitude, indeed reflect the globally averaged ${ }^{14} \mathrm{C}$ production rates. Changes in the carbon cycle can potentially have an impact on the ${ }^{14} \mathrm{C}$ concentration in the atmosphere. However, atmospheric ${ }^{14} \mathrm{C}$ concentrations are not very sensitive to carbon cycle changes (e.g. Siegenthaler et al., 1980) and, therefore, such influences should be minor during the climatically stable Holocene period that we discuss in this paper.

By contrast to ${ }^{14} \mathrm{C},{ }^{10} \mathrm{Be}$ stays in the atmosphere and is transported and deposited following the atmospheric aerosols within circa 1 yr only. Due to the geomagnetic shielding the solar induced changes in the radionuclide production rates are larger at the poles than at the equator. This has led to suggestions that there could be a polar bias in ${ }^{10} \mathrm{Be}$ records from ice cores from the polar ice caps (Bard et al., 1997; Mazaud and Bender, 1994). This has recently been investigated in detail by employing three-dimensional general circulation models that also include aerosol chemistry (Field et al., 2006; Heikkilä et al., 2008, 2009). These studies show that ${ }^{10} \mathrm{Be}$, especially the most modulated fraction at high latitudes, is mainly produced in the stratosphere. The stratosphere is stably layered allowing for a long residence time of aerosols and a smoothing out of gradients in aerosol concentrations. Thereafter, ${ }^{10} \mathrm{Be}$ is transported into the troposphere, mainly at mid-latitudes, where it is subjected to tropospheric transport and removal by rain or dry deposition.

The atmosphere is a non-linear system and the models require high resolution in order to fully resolve the transport processes of atmospheric particles. In any numerical model there is always some numerical diffusion in addition to physical diffusion. Numerical diffusion arises when, for modelling purposes, continuous systems are discretized and exchange processes are calculated in discrete spatial steps. The use of a coarse resolution tends to increase numerical diffusion. Unfortunately it is impossible to distinguish between numerical and physical diffusion. If numerical diffusion overrules physical diffusion in the model particles spread out too rapidly in horizontal and in vertical direction. This would lead to a too short residence time of ${ }^{10} \mathrm{Be}$ in the stratosphere and ${ }^{10} \mathrm{Be}$ would be transported too rapidly to lower levels. If this occurs to particles at polar latitudes, they would not undergo the transport over the mid-latitudes, and the change in the modelled deposition fluxes at polar latitudes would be larger than in reality. The different response of polar deposition to production changes between ModelE (showing a polar bias; Field et al., 2006) and ECHAM5-HAM (no polar bias; Heikkilä et al., 2008, 2009) can probably be explained by the different resolution of the models. Intercomparison of these models indicates that mixing of aerosols is limited in ModelE as, compared with other models, it has the coarsest resolutions (Textor et al., 2006).

The model study by Heikkilä et al. (2009) quantifies the fractions of ${ }^{10} \mathrm{Be}$ transported to polar latitudes from differ- ent parts of the atmosphere. In present day climate and solar activity ca. $65 \%$ of ${ }^{10} \mathrm{Be}$ is produced in the stratosphere, where it undergoes throughout mixing during its long residence time. A polar bias could be possible if 1) the fraction of ${ }^{10} \mathrm{Be}$ produced locally in the polar troposphere was large or 2) ${ }^{10} \mathrm{Be}$ produced in the polar stratosphere was deposited rapidly after production before undergoing mixing. According to Heikkilä et al. (2009) the fraction of ${ }^{10} \mathrm{Be}$ produced in the polar troposphere is $10-20 \%$ of the polar deposition fluxes. This fraction is not large enough to contribute to a detectable polar bias because the production modulation is quite weak in low altitudes. The strongly modulated ${ }^{10} \mathrm{Be}$ produced in the polar stratosphere would lead to a polar bias if it was deposited directly to polar latitudes. The process responsible for such direct deposition is gravitational settling. It is included in the models but contributes only to less than $5 \%$ of the total deposition. The lack of evidence for 1) or 2) in the model study explains the absence of a polar bias.

The modelling shows that, if significant changes in the precipitation or atmospheric circulation patterns have taken place in the past, the relative changes of ${ }^{10} \mathrm{Be}$ concentrations could potentially have been influenced during the period of change in regions where patterns shifted (Heikkilä et al., acc.). However, it is not expected that these could lead to systematic alterations of the amplitudes in the ${ }^{10} \mathrm{Be}$ records if there is no persistent connection between cosmic ray/solar variations and climate $/{ }^{10} \mathrm{Be}$ deposition in the region where the ${ }^{10} \mathrm{Be}$ record originates. Such potential biases are best detected by comparison to other cosmogenic radionuclide records, as is made in this study.

In the following we will base our discussion on the most recent high-resolution climate model results that suggest that there is no systematic polar bias in the ${ }^{10} \mathrm{Be}$ data. We will evaluate this hypothesis by comparing ${ }^{10} \mathrm{Be}$ and ${ }^{14} \mathrm{C}$ records.

\section{$3{ }^{14} \mathrm{C}$-based solar variations during the last 1000 years}

Figure 3 shows the ${ }^{14} \mathrm{C}$ production rate reconstruction (Muscheler et al., 2007) based on the Intcal04 ${ }^{14} \mathrm{C}$ data (Reimer et al., 2004) and an annual ${ }^{14} \mathrm{C}$ record measured by Stuiver and Braziunas (1998). There has been a debate on how to best normalise this record since fossil fuel burning (Suess, 1953) and nuclear bomb tests have significantly influenced the ${ }^{14} \mathrm{C}$ levels in the atmosphere. While the fossil fuel burning can be included in the calculation of the ${ }^{14} \mathrm{C}$ production rate (Muscheler et al., 2007) it, however, adds to the uncertainties of the ${ }^{14} \mathrm{C}$ trend in the first part of the $20^{\text {th }}$ century. The nuclear weapon tests completely overshadow the natural ${ }^{14} \mathrm{C}$ variations and make solar activity reconstructions impossible for the period of the strong anthropogenic ${ }^{14} \mathrm{C}$ increase in the second part of the $20^{\text {th }}$ century. Therefore, there is only a limited overlap between ${ }^{14} \mathrm{C}$-based and instrumental cosmic ray records such as neutron monitor data and ionization chamber data (McCracken and Beer, 2007). Conse- 
quently, the connection between the ${ }^{14} \mathrm{C}$ record and modern cosmic ray observations includes some uncertainties. ${ }^{10} \mathrm{Be}$ records, available up to date, cannot resolve these normalisation uncertainties since there are unexplained differences between records from Greenland and Antarctica (e.g. Raisbeck and Yiou, 2004). The uncertainties in relating todays solar activity to the cosmogenic radionuclide-based solar activity reconstructions can be reduced by applying the amplitude considerations outlined above.

For example, we can assume that the maximum levels in cosmogenic radionuclide production rates during the Maunder minimum (from approx. 1645 to $1715 \mathrm{AD}$ ) correspond to a complete absence of solar shielding of galactic cosmic rays (upper dotted line in Fig. 3). This would correspond to the lowest possible limit of solar activity during the Maunder minimum. As mentioned above, Masarik and Beer (1999, 2009) estimated a $70 \%$ increase in the global ${ }^{14} \mathrm{C}$ production rate from recent average solar activity levels to an absent solar shielding. Therefore, the lower dotted line in Fig. 3 indicates average solar activity levels of the last $60 \mathrm{yr}$ if the Maunder minimum indeed was characterized by an intermittent complete lack of solar modulation of cosmic rays. It indicates even higher levels if solar modulation was not completely absent during the Maunder minimum.

Geomagnetic field changes during the last $1000 \mathrm{yr}$ are of minor importance in this discussion as long as one does not compare periods that are characterised by strongly varying geomagnetic field strength. For example, with these considerations one can infer that solar activity levels before and after the Maunder minimum must have been similar or higher compared to average solar activity levels during the last $60 \mathrm{yr}$. However, it is problematic to compare Maunder minimum levels with e.g. the solar modulation around $1000 \mathrm{AD}$ since there was a considerable long-term geomagnetic field decrease during the last $3000 \mathrm{yr}$ (e.g. Knudsen et al., 2008). This has led to an increase in the ${ }^{14} \mathrm{C}$ production rate during this period. For reliable solar activity reconstructions of the absolute solar modulation levels this has to be corrected for. The large uncertainties in the geomagnetic field reconstructions then transfer directly into uncertainties in the solar activity reconstructions.

We can remove this uncertainty using the results shown in Fig. 2. As long as we concentrate on relative changes on relatively short time scales, where we can assume that geomagnetic field changes were minor, we can infer robust lower limits of solar activity in the past. Geomagnetic field uncertainties do not influence the results as long as very low geomagnetic field intensities are not reached. This was the case for example during the last approx. $11500 \mathrm{yr}$ (The Holocene) when geomagnetic field intensities below half of the present levels were never reached (e.g. Knudsen et al., 2008).

To conclude, Fig. 3 suggests that solar modulation levels around 1400, 1600 and $1800 \mathrm{AD}$ were similar or higher than the average solar activity levels during the last $60 \mathrm{yr}$ since the relative increase in the ${ }^{14} \mathrm{C}$ production rate is similar to

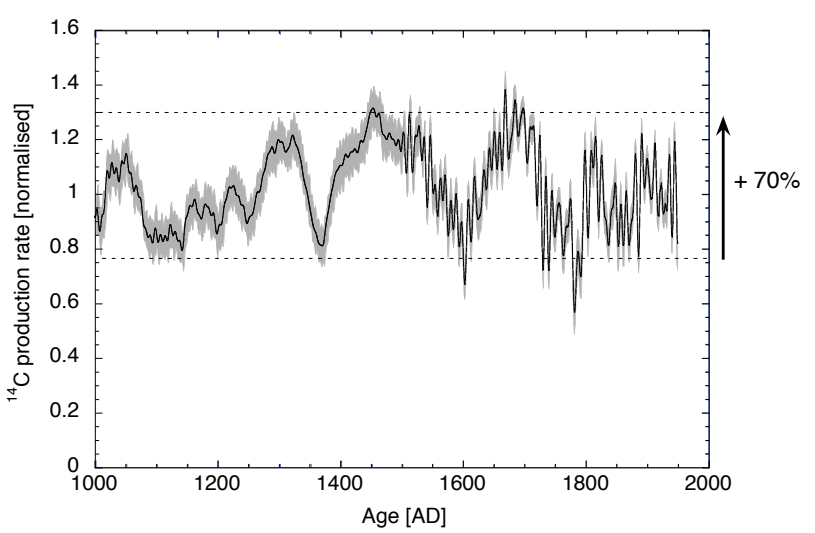

Fig. 3. ${ }^{14} \mathrm{C}$ production rate variations during the last $1000 \mathrm{yr}$ (Muscheler et al., 2007). The upper dashed line indicates maximal ${ }^{14} \mathrm{C}$ production rate levels. Assuming that these correspond to an absent solar shielding we obtain the lower dashed lines as solar activity levels that correspond to recent average levels of solar activity.

the increase that we can expect from todays solar shielding to an absent shielding. Geomagnetic field variations can be neglected in this discussion since we concentrate on changes on short time scales (e.g. we compare Maunder minimum levels (around $1700 \mathrm{AD}$ ) to the solar maxima just before and after the Maunder minimum) where the geomagnetic field intensity variations are insignificant for the ${ }^{14} \mathrm{C}$ variability.

\section{$4{ }^{10} \mathrm{Be}$ and ${ }^{14} \mathrm{C}$ during the Holocene}

The amplitude discussion exemplified for the last $1000 \mathrm{yr}$ can be applied to the complete Holocene period. In this case it is even harder to accurately reconstruct solar activity levels since geomagnetic field uncertainties increase further back in time. In addition, cosmogenic radionuclide records exhibit unexplained differences on longer time scales (Vonmoos et al., 2006; Muscheler et al., 2004).

We will discuss the ${ }^{10} \mathrm{Be}$ records from the two neighbouring Greenland Ice Core Project (GRIP) and Greenland Ice Sheet Project 2 (GISP2) ice cores from Central Greenland (Vonmoos et al., 2006; Muscheler et al., 2004; Finkel and Nishiizumi, 1997). In addition, we will use the ${ }^{14} \mathrm{C}$ production rate inferred from the ${ }^{14} \mathrm{C}$ calibration record (Muscheler et al., 2005; Reimer et al., 2004). Reconstructing and discussing the ${ }^{14} \mathrm{C}$ production rate removes as much as possible known effects of the carbon cycle on the atmospheric ${ }^{14} \mathrm{C}$ concentration (such as e.g. the dampening effect). Comparison of the radionuclide data to geomagnetic field reconstructions have shown that it is difficult to distinguish between solar and geomagnetic field influences on the cosmogenic radionuclides. Often it is assumed that geomagnetic field changes have a significant influence on the radionuclide production rates on longer time scales whereas solar activ- 


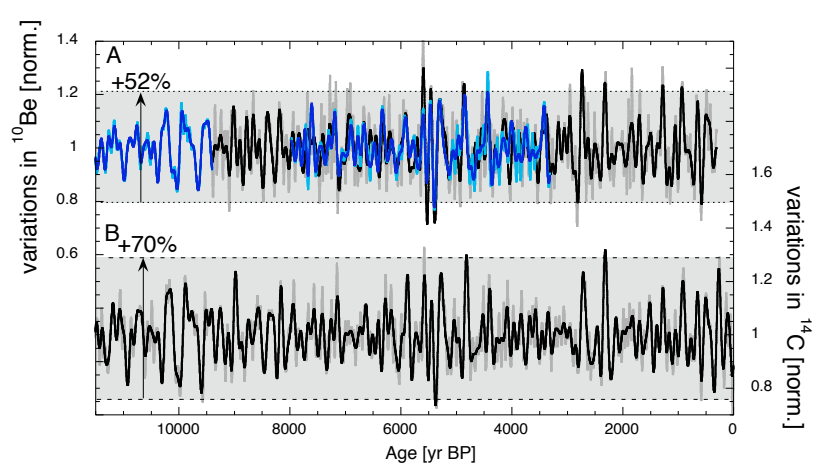

Fig. 4. Relative variations in the ${ }^{10} \mathrm{Be}$ concentrations from the GRIP (panel A: black) and GISP2 (panel A: blue) ice cores from Central Greenland and the ${ }^{14} \mathrm{C}$ production rate (panel B). The grey shading indicates the range of variability from absent solar modulation to average solar activity during recent solar cycles. The thick lines show variations on time scales between 100 and $500 \mathrm{yr}$ and the thin lines between 50 and $500 \mathrm{yr}$ (details: see text).

ity changes act rather on shorter time scales. It is unclear if this distinction is justified and which time scales are best to divide up solar and geomagnetic field changes. It has been shown that on time scales of $3000 \mathrm{yr}$ and longer the variations in cosmogenic radionuclides can be well explained by geomagnetic field changes (Muscheler et al., 2005; Wagner et al., 2000). Using high-resolution geomagnetic field reconstructions Snowball and Muscheler (2007) showed that the geomagnetic field influence becomes important on time scales of $500 \mathrm{yr}$ and longer. However, these results depend on the limited resolution and accuracy of the geomagnetic field reconstructions.

In the following we will assume that on time scales shorter than $500 \mathrm{yr}$ the solar influence on cosmogenic radionuclides is dominant and, due to limited temporal resolution of the data, we concentrate on time scales longer than $50 \mathrm{yr}(100 \mathrm{yr}$ respectively) to illustrate the solar activity changes on centennial time scales. Figure 4 shows the low-pass filtered (cut-off frequencies $1 / 50 \mathrm{yr}$ and $1 / 100 \mathrm{yr}$, respectively) ${ }^{10} \mathrm{Be}$ and ${ }^{14} \mathrm{C}$ records divided by their longer-term changes on time scales of $500 \mathrm{yr}$ and longer (division by the data after filtering with a cut-off frequencies of $1 / 500 \mathrm{yr}$ ). Thus, we infer the relative variations of the cosmogenic radionuclide after applying the following procedure:

$\operatorname{Var}_{14} \mathrm{C}={ }^{14} \mathrm{C}_{l p 50(l p 100)} /{ }^{14} \mathrm{C}_{l p 500}$

and

$\operatorname{Var}_{10} \mathrm{Be}={ }^{10} \mathrm{Be}_{l p 50(l p 100)} /{ }^{10} \mathrm{Be}_{l p 500}$

$l p 50, l p 100$ and $l p 500$ denote the different applied low-pass filters. This means that we focus exclusively on the relative variations around the longer-term mean. Consequently, we remove long-term changes in solar activity on time scales longer than $500 \mathrm{yr}$ but we also remove, as much as possible,
Table 1. Standard deviations of normalised production rate variations from Fig. 4 for the different radionuclide records and different periods of overlap. For ${ }^{10} \mathrm{Be}$ the numbers in brackets indicate the corresponding values for the ${ }^{10} \mathrm{Be}$ flux (Flux $={ }^{10} \mathrm{Be}$ concentration*accumulation rate*density of ice) which takes into account the potential influence of a varying snow accumulation rate on the ${ }^{10} \mathrm{Be}$ deposition rate. For ${ }^{14} \mathrm{C}$ the numbers in brackets indicate the variations diminished by about $25 \%$ to account for the expected production rate differences between ${ }^{10} \mathrm{Be}$ and ${ }^{14} \mathrm{C}$.

\begin{tabular}{lccc}
\hline $\begin{array}{l}\text { Period } \\
\text { Data set }\end{array}$ & $\begin{array}{c}11600-9400 \\
\text { yr BP }\end{array}$ & $\begin{array}{c}3310-7970 \\
\text { yr BP }\end{array}$ & $\begin{array}{c}310-9400 \\
\text { yr BP }\end{array}$ \\
\hline${ }^{14} \mathrm{C}$ production rate & 0.101 & 0.099 & 0.098 \\
$(1 / 50 \div 1 / 500$ yr $)$ & $(0.076)$ & $(0.074)$ & $(0.074)$ \\
\hline${ }^{14} \mathrm{C}$ production rate & 0.093 & 0.084 & 0.087 \\
$(1 / 100 \div 1 / 500$ yr $)$ & $(0.070)$ & $(0.063)$ & $(0.065)$ \\
\hline GISP2 ${ }^{10} \mathrm{Be}$ & 0.072 & 0.077 & - \\
$(1 / 50 \div 1 / 500 \mathrm{yr})$ & $(0.085)$ & $(0.093)$ & \\
\hline GISP2 ${ }^{10} \mathrm{Be}$ & 0.070 & 0.071 & - \\
$(1 / 100 \div 1 / 500 \mathrm{yr})$ & $(0.080)$ & $(0.078)$ & \\
\hline GRIP ${ }^{10} \mathrm{Be}$ & - & 0.108 & 0.108 \\
$(1 / 50 \div 1 / 500 \mathrm{yr})$ & & $(0.113)$ & $(0.111)$ \\
\hline GRIP ${ }^{10} \mathrm{Be}$ & - & 0.082 & 0.085 \\
$(1 / 100 \div 1 / 500 \mathrm{yr})$ & & $(0.081)$ & $(0.083)$ \\
\hline
\end{tabular}

the geomagnetic field uncertainty in the discussion. Again, by assuming that the maximum radionuclide production rates correspond to absent solar shielding (as a lower limit) we can obtain lower limits for solar activity levels throughout the Holocene.

Even with the absent 11-yr cycle and any additional solar variations on time scales shorter than $50 \mathrm{yr}$ we observe that the ${ }^{14} \mathrm{C}$ variations are often close to the $70 \%$ range from an absent solar modulation to average solar modulation levels of the last $60 \mathrm{yr}$. This implies that e.g. around $5500 \mathrm{yr}$ BP solar activity levels had to exceed the levels that we observed during the satellite era. It is also clear that there are periods of a generally more stable solar activity where the range of variability is smaller (e.g. around $3500 \mathrm{yr} \mathrm{BP}$ ). Due to uncertainties in the ${ }^{10} \mathrm{Be}$ and ${ }^{14} \mathrm{C}$ data and the geomagnetic field reconstructions any conclusion about absolute solar activity levels are uncertain. Periods of decreased variability could represent generally increased or decreased solar modulation or a mix thereof. During periods of less expressed solar variations on centennial time scales we see stronger activity in the shorter-term range (e.g. $88 \mathrm{yr}$ cycle - see thin lines in Fig. 4).

The ${ }^{10} \mathrm{Be}$ and ${ }^{14} \mathrm{C}$ variations agree generally very well. However, the ${ }^{10} \mathrm{Be}$ data suggests an even larger range of variability in solar modulation as the ${ }^{14} \mathrm{C}$ data considering the stronger sensitivity of ${ }^{14} \mathrm{C}$ production rate variations compared to ${ }^{10} \mathrm{Be}$. If we look at the suggested $52 \%$ range from absent solar shielding to recent solar activity levels we ob- 
serve that the ${ }^{10} \mathrm{Be}$ data covers this range without longer interruptions during basically the complete Holocene period. This suggests that, based on the ${ }^{10} \mathrm{Be}$ data, there is hardly any possibility for sustained solar activity levels below present day conditions. The difference in variability in the ${ }^{10} \mathrm{Be}$ and ${ }^{14} \mathrm{C}$ data is also illustrated by the comparison presented in Table 1. It shows the results of a simple calculation of the standard deviations around the mean of the data presented in Fig. 4. It indicates that the GISP2 and GRIP data have a significantly different range of variability and the variability of the GISP2 data lies very close to the range of variability in ${ }^{14} \mathrm{C}$ (after accounting for the production rate differences). Calculating the ${ }^{10} \mathrm{Be}$ flux does not change the overall picture but it increases the variability in the data slightly. The biggest difference, however, is apparent when we compare the ${ }^{14} \mathrm{C}$ production rate and the GRIP ${ }^{10} \mathrm{Be}$ data. The variability in the GRIP ${ }^{10} \mathrm{Be}$ record is about $30 \%$ larger than the variability in the ${ }^{14} \mathrm{C}$ data. Thus, the discussion of reasons behind the ${ }^{10} \mathrm{Be}$ and ${ }^{14} \mathrm{C}$ differences is important since the GRIP ${ }^{10} \mathrm{Be}$ data sets stronger limits to past solar activity levels than the ${ }^{14} \mathrm{C}$ data or the GISP $2{ }^{10} \mathrm{Be}$ data.

The GRIP and the GISP2 ${ }^{10} \mathrm{Be}$ data have been measured in ice cores from Central Greenland that were recovered only $30 \mathrm{~km}$ apart from each other. Therefore, we do not expect systematic differences in the ${ }^{10} \mathrm{Be}$ deposition rates at the two sites. The most obvious difference and likely reason behind the differences is the different temporal resolution of the records. The GRIP ${ }^{10} \mathrm{Be}$ record has an average resolution of $5 \mathrm{yr}$ and the GISP2 record has only an average resolution of $35 \mathrm{yr}$. This can explain about $10 \%$ of the difference between the GRIP and GISP2 data on time scales from 50 to 500 yr. We obtain this estimate from a calculation where we artificially reduced the resolution of the GRIP data by averaging these data onto the GISP2 time scale. The increased variability in the ${ }^{10} \mathrm{Be}$ flux compared to the ${ }^{10} \mathrm{Be}$ concentration also points to a time resolution issue. To calculate the flux we multiplied the ${ }^{10} \mathrm{Be}$ concentration with the reconstructed snow accumulation rate. For this we retained the higher resolution accumulation rate record which then leads to the higher range of variability in the GISP2 (and GRIP) ${ }^{10} \mathrm{Be}$ flux data. On the other hand, smoothing due to low data resolution can also minimize the influence of "weather noise" in the data. For example, the GRIP ${ }^{10} \mathrm{Be}$ record includes high-resolution changes that cannot be interpreted in terms of production rate changes. These are removed to a large degree by concentrating on variations on time scales longer than $50 \mathrm{yr}$ but they might still leave some imprint in the filtered records. In conclusion, it is very likely that the low-resolution GISP2 ${ }^{10} \mathrm{Be}$ record underestimates the production rate variability. The variability in the high-resolution GRIP ${ }^{10} \mathrm{Be}$ record represents short-term changes more accurately but it might also reflect processes unrelated to production rate changes.

Figure 4 suggests that all of the major peaks in the ${ }^{10} \mathrm{Be}$ and ${ }^{14} \mathrm{C}$ records are indeed related to production rate vari- ations. The range of variability in the ${ }^{14} \mathrm{C}$ production rate and the GISP2 ${ }^{10} \mathrm{Be}$ is very similar after correcting for the expected differences in the ${ }^{10} \mathrm{Be}$ and ${ }^{14} \mathrm{C}$ production rates (Table 1). Obviously, the GRIP ${ }^{10} \mathrm{Be}$ data shows larger variability than the ${ }^{14} \mathrm{C}$ data. Again, the underlying reason is likely to be connected to the different time resolution of the data. The Intcal04 record is composed of many different ${ }^{14} \mathrm{C}$ records and considerable smoothing has been applied to extract the robust features of the data (Reimer et al., 2004). A data-related smoothing leads to smaller amplitudes of variability and, therefore, correcting for the smoothing would then increase the range of variability. As we will discuss below a potential bias in the reconstruction of the ${ }^{14} \mathrm{C}$ production rate could be an additional factor for the ${ }^{10} \mathrm{Be} /{ }^{14} \mathrm{C}$ differences but it is unlikely to lead to stronger ${ }^{14} \mathrm{C}$ variability. Production rate differences between ${ }^{10} \mathrm{Be}$ and ${ }^{14} \mathrm{C}$ (Masarik and Beer, 1999, 2009; Lal, 1988) and a small polar bias in the ${ }^{10} \mathrm{Be}$ data (undetectable in the most recent general circulation model runs) might be also relevant in this discussion. However, it is impossible to pinpoint the exact source of the differences between the GRIP ${ }^{10} \mathrm{Be}$ and ${ }^{14} \mathrm{C}$ data. Therefore, we will refrain from strong conclusions based on the GRIP ${ }^{10} \mathrm{Be}$ data alone. In the following section we will discuss additional sources of errors and their impact on our results.

\section{Discussion}

The discussion of the relative amplitudes in cosmogenic radionuclide records allows us to infer lower limits for solar activity levels in the past. This approach is more robust than the traditional approach where geomagnetic field reconstructions with relatively large uncertainties were included in the calculation to isolate the solar signal. However, our approach still contains considerable uncertainties. In the following we will discuss these uncertainties and evaluate if they are likely to question the conclusions of our analysis.

Production rate uncertainties: We were basing our discussion on the results by Masarik and Beer (1999, 2009). Their updated calculations about the relative changes in the radionuclide production rates confirm earlier results and are also in agreement with the result by e.g. Lal (1988). It is important to note that this does not apply to the absolute levels of the radionuclide production rates that, however, do not play a role in our discussion. Using the updated local interstellar spectra Webber and Higbie (2010) inferred a more limited potential for solar induced variations on the ${ }^{10} \mathrm{Be}$ production rate. They estimate a maximum possible increase of 1.5 for absent solar shielding compared to recent solar activity levels. Since this estimate refers to polar areas the globally averaged increase in the ${ }^{10} \mathrm{Be}$ production rate is even smaller. This agrees with the discussion outlined above that fewer particles in the LIS reduce the potential for ${ }^{10} \mathrm{Be}$ and ${ }^{14} \mathrm{C}$ production rate increases. Therefore, we included relatively conservative estimates for ${ }^{10} \mathrm{Be}$ and ${ }^{14} \mathrm{C}$ production 
rate increases. If we adopted the smaller values by Webber and Higbie (2010) we would obtain even stronger constraints about solar activity levels in the past i.e. an even reduced possibility for sustained periods of low solar activity levels.

Table 1 indicates that there are differences in the variability of the different radionuclide records. Interesting in this context is the suggested polar bias of the ${ }^{10} \mathrm{Be}$ data. The GRIP ${ }^{10} \mathrm{Be}$ data exhibits indeed a larger variability than the ${ }^{14} \mathrm{C}$ production rate data after it is corrected for the expected production rate differences. However, the figure is not consistent because the GISP $2{ }^{10} \mathrm{Be}$ record does not show a larger variability than ${ }^{14} \mathrm{C}$. As discussed in Sect. 2.3., new model calculations show no realistic ${ }^{10} \mathrm{Be}$ pathways that could transfer an enhanced polar production rate signal into the troposphere (Heikkilä et al., 2008, 2009). Therefore, we regard a polar bias in the ${ }^{10} \mathrm{Be}$ data as an unlikely explanation for the main differences between GRIP ${ }^{10} \mathrm{Be}$ and ${ }^{14} \mathrm{C}$.

While ${ }^{14} \mathrm{C}$ is well mixed in the atmosphere on a global scale there are some uncertainties involved in the reconstruction of the ${ }^{14} \mathrm{C}$ production rate. It is unlikely that carbon cycle changes had a significant impact on the short-term changes in ${ }^{14} \mathrm{C}$ (Siegenthaler et al., 1980) but there are some uncertainties involved in the carbon cycle models itself. Delaygue and Bard (2010) show a range of model results that exhibit differences in the attenuation and phase lags of atmospheric ${ }^{14} \mathrm{C}$ changes. These uncertainties directly transfer into uncertainties in the reconstructed ${ }^{14} \mathrm{C}$ production rate. For example, for typical solar variations with durations of $200 \mathrm{yr}$ Delaygue and Bards models have attenuation factors ranging from 0.05 to 0.06 . This means that the reconstructed ${ }^{14} \mathrm{C}$ production rate can include biases in this range depending on the applied carbon cycle model. Our box-diffusion model (Oeschger et al., 1975; Siegenthaler, 1983) is at the lower limit in this attenuation range which implies that the reconstructed ${ }^{14} \mathrm{C}$ production rate is at the upper range of the models investigated by Delaygue and Bard (2010). Nevertheless, as mentioned above our model results agree well with newer 3-D carbon cycle models which suggests that the range of relatively simple models adopted by Delaygue and Bard (2010) might overestimate the uncertainties than we can expect.

Geomagnetic field behaviour: Our approach eliminates to a large extent uncertainties in the geomagnetic field intensity. Nevertheless, even if there is no evidence for significant and strong geomagnetic dipole field intensity changes on time scales shorter than $500 \mathrm{yr}$ such changes cannot be excluded. This contributes to the uncertainties in the inferred solar activity variations on shorter time scales and such changes would then still be visible in Fig. 4. However, a systematic geomagnetic field-related bias of the amplitudes of the variations shown in Fig. 4 is unlikely.

Limited data resolution: There is no high-resolution cosmogenic radionuclide record with high enough resolution to trace the solar 11-yr cycle throughout the Holocene. Figure 3 shows that the 11-yr cycle adds to the variability even during periods of a very quiet Sun. Comparison of Fig. 3 and Fig. 4 indicates that the amplitude discussion should be narrowed down by about $10 \%$ to accommodate for the fact of the varying solar activity even during periods of a quiet Sun. This does not apply for the high solar activity levels since we did the comparison to an average solar modulation of the last $60 \mathrm{yr}$.

\section{Conclusions}

With an analysis of the range of variability of cosmogenic radionuclide record we obtain lower limits for the solar activity levels during the Holocene. Overall, there are several uncertainties involved in this discussion. However, the majority of the uncertainties would lead to even larger inferred solar amplitudes (new LIS, data-related smoothing, absence of the shorter-term $(<50 \mathrm{yr})$ solar variability). Some uncertainties could lead to smaller amplitudes (noise in ${ }^{10} \mathrm{Be}$, carbon cycle bias in ${ }^{14} \mathrm{C}$ calculation) and some uncertainties cannot be quantified (short-term geomagnetic field changes). Even if we base our conclusions on a very conservative approach with probably overestimated effects of solar modulation and using smoothed data $\left(\right.$ e.g. $\left.{ }^{14} \mathrm{C}\right)$ we obtain evidence that present solar activity levels were not unique and that these occurred on a regular basis. Especially for periods of highly variable ${ }^{10} \mathrm{Be}$ and ${ }^{14} \mathrm{C}$ production rates (e.g. around $5000 \mathrm{yr}$ BP, $2500 \mathrm{yr} \mathrm{BP}, 500 \mathrm{yr} \mathrm{BP}$ ) we can conclude that the solar modulation occasionally equalled or exceeded recent levels. It is very likely that the GISP2 and ${ }^{14} \mathrm{C}$ data underestimate the production rate variations due to data-related smoothing which suggests that there are more periods that can be constrained in a similar way (e.g. around $10000 \mathrm{yr}$ BP). Future progress in understanding the geochemical behaviour of ${ }^{10} \mathrm{Be}$ and ${ }^{14} \mathrm{C}$, improved ${ }^{10} \mathrm{Be} /{ }^{14} \mathrm{C}$ production rate calculations and LIS spectra can lead to even stronger constraints about past solar activity levels with our method. Since we estimate the lower limits only we cannot rule out that sustained levels of higher solar activity occurred in the past.

Acknowledgements. This work was supported by the Swedish National Science foundation. RM is supported by the Royal Swedish Academy of Sciences through a grant financed by the Knut and Alice Wallenberg Foundation.

Edited by: B. Heber

Reviewed by: two anonymous referees

\section{References}

Bard, E., Raisbeck, G. M., Yiou, F., and Jouzel, J.: Solar modulation of cosmogenic nuclide production over the last millennium: comparison between ${ }^{14} \mathrm{C}$ and ${ }^{10} \mathrm{Be}$ records, Earth Planet. Sc. Lett., 150, 453-462, 1997. 
Burger, R. A., Potgier, M. S., and Heber, B.: Rigidity dependence of cosmic ray proton latitudinal gradients measured by the Ulysses spacecraft: Implications for the diffusion tensor, J. Geophys. Res., 105, 447-427, 455, 2000.

Delaygue, G. and Bard, E.: An Antarctic view of Beryllium10 and solar activity for the past millennium, Clim. Dynam., doi:10.1007/s00382-00010-00795-00381, 2010.

Field, C. V., Schmidt, G. A., Koch, D., and Salyk, C.: Modeling production and climate-related impacts on ${ }^{10} \mathrm{Be}$ concentration in ice cores, J. Geophys. Res., 111, D15107, doi:15110.11029/12005JD006410, 2006.

Finkel, R. C. and Nishiizumi, K.: Beryllium 10 concentrations in the Greenland ice sheet project 2 ice core from 3-40 ka, J. Geophys. Res., 102, 26699-26706, 1997.

Garcia-Munoz, M., Mason, G. M., and Simpson, J. A.: The anomalous $4 \mathrm{He}$ component in the cosmic-ray spectrum at $\leq 50 \mathrm{MeV}$ per nucleon during 1972-1974, Astrophys. J., 202-265, 1975.

Gleeson, L. J. and Axford, W. I.: Solar Modulation of Galactic Cosmic Rays, Astrophys. J., 154, 1011-1026, 1968.

Heikkilä, U., Beer, J., and Feichter, J.: Modeling cosmogenic radionuclides ${ }^{10} \mathrm{Be}$ and $7 \mathrm{Be}$ during the Maunder Minimum using the ECHAM5-HAM General Circulation Model, Atmos. Chem. Phys., 8, 2797-2809, 2008,

http://www.atmos-chem-phys.net/8/2797/2008/.

Heikkilä, U., Beer, J., and Feichter, J.: Meridional transport and deposition of atmospheric ${ }^{10} \mathrm{Be}$, Atmos. Chem. Phys., 9, 515527,2009 , http://www.atmos-chem-phys.net/9/515/2009/.

Heikkilä, U., Abreu, J. A., Beer, J., and Steinhilber, F.: On the atmospheric transport and deposition of the cosmogenic radionuclides $\left({ }^{10} \mathrm{Be}\right)$ : a review, Space Sci. Rev., accepted.

Knudsen, M. F., Riisager, P., Donadoni, F., Snowball, I., Muscheler, R., and Pesonen, L.: Variations in the geomagnetic dipole moment during the Holocene and the past $50 \mathrm{kyr}$, Earth Plan. Sci. Lett., 272, 319-329, doi:310.1016/j.epsl.2008.1004.1048, 2008.

Knudsen, M. F., Riisager, P., Jacobsen, B. H., Muscheler, R., Snowball, I., and Seidenkrantz, M.-S.: Taking the pulse of the Sun during the Holocene by joint analysis of ${ }^{14} \mathrm{C}$ and ${ }^{10} \mathrm{Be}$, Geophys. Res. Lett., 36, L16701, doi:16710.11029/12009GL039439, 2009.

Lal, D.: Theoretically Expected Variations in the Terrestrial Cosmic-Ray Production Rates of Isotopes, in: Solar Terrestrial Relationships and the Earth Environment in the last Millennia, edited by: Castagnoli, G. C., Proceedings of the International School of Physics "Enrico Fermi", North-Holland, Amsterdam, 215-233, 1988.

Lal, D. and Peters, B.: Cosmic Ray Produced Radioactivity on the Earth, in: Handbuch für Physik, edited by: Flügge, S., Springer, Berlin, 551-612, 1967.

Masarik, J. and Beer, J.: Simulation of particle fluxes and cosmogenic nuclide production in the Earth's atmosphere, J. Geophys. Res., 104, 12099-012111, 1999.

Masarik, J. and Beer, J.: An updated simulation of particle fluxes and cosmogenic nuclide production in the Earths atmosphere, J. Geophys. Res., 114, D11103, doi:11110.11029/12008JD010557, 2009.

Mazaud, A., C., L. and Bender, M.: A geomagnetic chronology for antarctic ice accumulation, Geophys. Res. Lett., 21, 337-340,
1994.

McCracken, K. G. and Beer, J.: Long-term changes in the cosmic ray intensity at Earth, 1428-2005, J. Geophys. Res., 112, A10101, doi:10.1029/2006JA012117., 2007.

McHargue, L. R. and Damon, P. E.: The global beryllium 10 cycle, Rev. Geophys., 29, 141-158, 1991.

Muscheler, R., Beer, J., Wagner, G., Laj, C., Kissel, C., Raisbeck, G. M., Yiou, F., and Kubik, P. W.: Changes in the carbon cycle during the last deglaciation as indicated by the comparison of ${ }^{10} \mathrm{Be}$ and ${ }^{14} \mathrm{C}$ records, Earth Planet. Sc. Lett., 219, 325-340, 2004.

Muscheler, R., Beer, J., Kubik, P. W., and Synal, H.-A.: Geomagnetic field intensity during the last 60000 years based on ${ }^{10} \mathrm{Be}$ and $36 \mathrm{Cl}$ from the Summit ice cores and ${ }^{14} \mathrm{C}$, Quaternary Sci. Rev., doi:10.1016/j.quascirev.2005.1001.1012, 2005.

Muscheler, R., Joos, F., Beer, J., Mueller, S. A., Vonmoos, M., and Snowball, I.: Solar activity during the last $1000 \mathrm{yr}$ inferred from radionuclide records, Quaternary Sci. Rev., 26, 82-97, doi:10.1016/j.quascirev.2006.1007.1012, 2007.

Oeschger, H., Siegenthaler, U., Schotterer, U., and Gugelmann, A.: A box diffusion model to study the carbon dioxide exchange in nature, Tellus, 27, 168-192, 1975.

Raisbeck, G. M. and Yiou, F.: Comment on "Millennium Scale Sunspot Number Reconstruction: Evidence for an Unusually Active Sun Since the 1940s", Phys. Rev. Lett., 92, DOI: 10.1103/PhysRevLett.1192.199001, 2004.

Reimer, P. J., Baillie, M. G. L., Bard, E., Bayliss, A., Beck, J. W., Bertrand, C. J. H., Blackwell, P. G., Buck, C. E., Burr, G. S., Cutler, K. B., Damon, P. E., Edwards, R. L., Fairbanks, R. G., Friedrich, M., Guilderson, T., Hogg, A. G., Hughen, K. A., Kromer, B., McCormac, G., Manning, S., Bronk Ramsey, C., Reimer, R. W., Remmele, S., Southon, J., Stuiver, M., Talamo, S., Taylor, F. W., van der Plicht, J., and Weyhenmeyer, C. E.: INTCAL04 Terrestrial Radiocarbon Age Calibration, 0-26 CAL KYR BP, Radiocarbon, 46, 1029-1058, 2004.

Siegenthaler, U.: Uptake of excess $\mathrm{CO} 2$ by an outcrop-diffusion model ocean, J. Geophys. Res., 88, 3599-3608, 1983.

Siegenthaler, U., Heimann, M., and Oeschger, H.: ${ }^{14} \mathrm{C}$ variations caused by changes in the global carbon cycle, Radiocarbon, 22, 177-191, 1980.

Snowball, I. and Muscheler, R.: Palaeomagnetic intensity data: An Achilles heel of solar activity reconstructions, Holocene, 17,6, 851-859, 2007.

Solanki, S. K., Usoskin, I. G., Kromer, B., Schüssler, M., and Beer, J.: Unusual activity of the Sun during recent decades compared to the previous 11,000 years, Nature, 431, 1084-1087, 2004.

Steinhilber, F., Abreu, J. A., and Beer, J.: Solar modulation during the Holocene, Astrophys. Space Sci. Trans., 4, 1-6, 2008.

Stuiver, M. and Braziunas, F.: Anthropogenic and solar components of hemispheric ${ }^{14} \mathrm{C}$, Geophys. Res. Lett., 25, 329-332, 1998.

Suess, H. E.: Natural Radiocarbon and the Rate of Exchange of Carbon Dioxide Between the Atmosphere and the Sea, in: Proceedings of the Conference on Nuclear Processes in Geological Settings, edited by: Science, N. R. C. C. o. N., Univ. of Chicago Press, Chicago, 52-56, 1953.

Textor, C., Schulz, M., Guibert, S., Kinne, S., Balkanski, Y., Bauer, S., Berntsen, T., Berglen, T., Boucher, O., Chin, M., Dentener, F., Diehl, T., Easter, R., Feichter, J., Fillmore, D., 
Ghan, S., Ginoux, P., Gong, S., Grini, A., Hendricks, J., Horowitz, L., Huang, P., Isaksen, I., Iversen, T., Kloster, S., Koch, D., Kirkevåg, A., Kristjansson, J. E., Krol, M., Lauer, A., Lamarque, J. F., Liu, X., Montanaro, V., Myhre, G., Penner, J., Pitari, G., Reddy, S., Seland, Ø., Stier, P., Takemura, T., and Tie, X.: Analysis and quantication of the diversities of aerosol life cycles within AeroCom, Atmos. Chem. Phys., 6, 1777-1813, 2006.

Usoskin, I. G., Alanko-Huotari, K., Kovaltsov, G. A., and Mursula, K.: Heliospheric modulation of cosmic rays: Monthly reconstruction for 1951-2004, J. Geophys. Res., 110, A12108, doi:12110.11029/12005JA011250, 2005.

Vonmoos, M., Beer, J., and Muscheler, R.: Large variations in Holocene solar activity: Constraints from ${ }^{10} \mathrm{Be}$ in the Greenland Ice Core Project ice core, J. Geophys. Res., 111, doi:10.1029/2005JA011500, 2006.

Wagner, G., Masarik, J., Beer, J., Baumgartner, S., Imboden, D., Kubik, P. W., Synal, H.-A., and Suter, M.: Reconstruction of the geomagnetic field between 20 and $60 \mathrm{kyr}$ BP from cosmogenic radionuclides in the GRIP ice core, Nucl. Instrum. Meth. B, B172, 597-604, 2000.
Webber, W. R. and Higbie, P. R.: Production of cosmogenic Be nuclei in the Earths atmosphere by cosmic rays: Its dependence on solar modulation and the interstellar cosmic ray spectrum, J. Geophys. Res., 108, 1355, doi:1310.1029/2003JA009863, 2003.

Webber, W. R. and Higbie, P. R.: Galactic propagation of cosmic ray nuclei in a model with an increasing diffusion coefficient at low rigidities: A comparison of the new interstellar spectra with Voyager data in the outer heliosphere, J. Geophys. Res., 114, A02103, doi:02110.01029/02008JA013689, 2009.

Webber, W. R. and Higbie, P. R.: What Voyager cosmic ray data in the outer heliosphere tells us about ${ }^{10} \mathrm{Be}$ production in the Earths polar atmosphere in the recent past, J. Geophys. Res., 115, A05102, doi:05110.01029/02009JA014532, 2010. 